\title{
SÉANCE DU 14 JUIN 1912
}

PRÉSIDENCE DE M. R. ZEILLER.

M. F. Camus, secrétaire, donne lecture du procès-verbal de la dernière séance, dont la rédaction est adoptée.

M. le Président a le regret d'annoncer le décès de trois de nos collègues, MM. Rolland, Ch. Malo et H. de Boissieu. A propos de la mort tragique de ce dernier, il s'exprime en ces termes :

M. Henri de Boissieu partit le 23 mai pour une excursion botanique sur le plateau d'Hostias dans l'Ain; il ne devait plus reparaitre, et près de trois cruelles semaines se sont écoulées sans qu'on pût retrouver sa trace. Les membres de la Société ont pris part aux angoisses des siens, sachant bien, eux qui le connaissaient, que sa disparition ne pouvait être imputable qu'à un accident; c'est seulement ces jours derniers qu'après de longues recherches on retrouvait son cadavre au pied d'un escarpement. Entré à la Société en 1894, M. de Boissieu nous avait donné de nombreuses Notes, tant sur la flore de l'Indo-Chine et de l'ExtrêmeOrient que sur la flore de ce département de l'Ain qu'il aimait à explorer et où il a si malheureusement péri, victime de son amour pour la science.

La Société perd en lui un membre particulièrement actif et assidu à ses séances, et éminemment sympathique.

M. le Président annonce ensuite deux nouvelles présentations.

M. Rouy offre à la Société le tome XIII et avant-dernier de sa Flore de France.

Le Président, au nom de la Société, remercie M. G. Rouy du don de ce volume et le félicite de l'avancement de cette belle œuvre, si appréciée de tous les botanistes, et dont l'Académie des Sciences était heureuse, il y a peu de jours, de consacrer la haute valeur, en attribuant le prix Jérôme Ponti a son auteur.

T. LIX.

(SÉANCES) 30 


\section{$2 \mathrm{BHL}$ Biodiversity Heritage Library}

1912. "Séance Du 14 Juin 1912." Bulletin de la Société botanique de France 59, 465-465. https://doi.org/10.1080/00378941.1912.10832451.

View This Item Online: https://www.biodiversitylibrary.org/item/8681

DOI: https://doi.org/10.1080/00378941.1912.10832451

Permalink: https://www.biodiversitylibrary.org/partpdf/157693

\section{Holding Institution}

Missouri Botanical Garden, Peter H. Raven Library

\section{Sponsored by}

Missouri Botanical Garden

\section{Copyright \& Reuse}

Copyright Status: Public domain. The BHL considers that this work is no longer under copyright protection.

This document was created from content at the Biodiversity Heritage Library, the world's largest open access digital library for biodiversity literature and archives. Visit BHL at https://www.biodiversitylibrary.org. 